\title{
THE REDUPLICATIVE COPULA IS IS
}

\author{
MICHAEL SHAPIRO \\ Brown University
}

\author{
MICHAEL C. HALEY \\ University of Alaska Anchorage
}

\section{$\mathrm{T}$}

he CURRENT PRESIDENT, George W. Bush, may be linguistically atypical of educated speakers in some ways, but he shares one grammatical trait with many others, namely, the nonstandard syntactic construction we will call provisionally, for lack of a better designation, the reduplicative copula, as in the following examples: "What I've said is is that..." (televised debate with $\mathrm{Al}$ Gore, 3 Oct. 2000); and even more incongruously, "My concerns ARE Is that..." (Vermont Public Radio, interview at Burlington Airport, 23 Oct. 1999). The second construction we have not observed in any other speaker, but the first is quite commonly heard, as in: "What I can say Is Is that ..." (Greg Maffei, Microsoft CFO, interviewed on CNN's Moneyline, 10 Nov. 1999); "The truth is Is that ..." (Ira Glasser, ACLU director, interviewed on NPR's Morning Edition, 27 Dec. 200o); "The secret truth was Is that work was my whole life" (character on the ABC soap opera Once and Again, 9 Nov. 2001); and "The good news is is that..." (Paula Dobriansky, under secretary of state for global affairs, interviewed on CNN's America's New War, 30 Nov. 2001). Examples such as these could be multiplied manyfold, as this is a widespread feature of contemporary speech (if absent from written English).

As far as we can determine, this syntactic phenomenon, particularly with sentence topic words like problem, was first discussed in print in Shapiro $(1993,12),{ }^{1}$ where the example cited was uttered by Hillary Clinton: "The ratio Is Is that ..." (excerpt from a speech to the American Hospital Association, CNN's Early Prime news broadcast, 9 Aug. 1993). Shapiro wondered whether the duplication could be some kind of emphasis or a hesitation phenomenon, "a vagary of performance, where the speaker isn't sure what they will assert in the rest of the sentence," and ventured the following commentary (which he no longer finds completely explanatory):

Perhaps we should regard it as a pleonasm, which, of course, is a kind of repetition. But the advantage of changing perspectives becomes clear when we also adopt the corollary position of interpreting copula reduplication as a concomitant of a boundary shift. ... Perhaps what we have here is the linearization of the redundant existential meaning that inheres in the simultaneous semantic syntagm of every topic word. The nouns problem, reason, and guess [in topic position] contain within their syntagms of signata the meaning of existing-albeit redundantly. The nonstandard construction $\mathrm{X}$ is is that $\mathrm{Y}$ can be interpreted as being the product of the 
"unpacking" of the simultaneous syntagm of the topic word X: the once covert existential $[s i c]$ copula is linearized immediately following the topic word, a process accompanied by a shift in the boundary of the relevant syntagm. [Shapiro $1993,12]^{2}$

The only other printed mention of the reduplicative copula we are aware of is in the introduction to Andrew Sihler's (2000, 9) new textbook of historical linguistics:

A very recent development in English is seen in sentences like The problem is is that the payment always arrives late. The innovation seems to consist of redefining The problem is as a sentence, which is the subject of the matrix sentence . . is that the payment always arrives late. This may somehow be traceable to structures like What the problem is is still unclear, where the syntax is transparent.

It might help to understand the reduplicative copula by placing it in the context of related constructions and considering how it might have arisen.

Consider the following series:

1. What I've said is is that...

2. My concerns ARE Is that...

3. What I can say is is that ...

4. The truth is is that...

5. The ratio is is that...

6. The problem is is that the payment always arrives late.

7. What the problem is is still unclear.

Most of these double-copula constructions have two other syntactic elements in common: they are all examples of (or similar to) the so-called "cleft sentence" construction (Kolln and Funk 1998, 126-27, 349-51), and, with the exception of ( 7 ), they have nominal (noun) that-clauses in the subject-complement slot. Below we will show how these two factors may be relevant to the occurrence of the reduplicative copula with a that-clause following.

Here is how the cleft works. Start with a simple basic proposition, like

Dostoevsky witnessed a murder,

and then "cleave" it into two clauses (the result being a "cleft" sentence). The payoff comes in the form of syntactic emphasis on one of the arguments in the basic proposition (either Dostoevsky or a murder, in this case):

It was Dostoevsky who witnessed a murder. [emphasis on Dostoevsky]

It was a murder that Dostoevsky witnessed. [emphasis on a murder] 
This construction seems to achieve emphasis by positioning the targeted argument at the end of the main clause, while relegating all other content to the subordinate clause. Under this arrangement, the targeted argument gets to occupy the whole main clause by itself, or almost so. The only other elements in the main clause are the redundant $I t$ and the grammatical copula (always some form of the verb $b e$ ).

An alternate version of the cleft is called the "wh-cleft." It, too, works by subordinating all other content except the targeted argument, but here the emphatic end-focus on the target is even stronger, on account of a longer delay of grammatical closure in the main clause:

What Dostoevsky witnessed was a murder.

By relegating all other content (Dostoevsky and witnessed) to a subordinate wh-clause serving as a nominal in the main subject position, this construction delays the presentation of the targeted argument (a murder) until the very end of the main clause. More importantly, the main clause does not achieve grammatical closure until the very end of the sentence. This long delay creates syntactic tension and semantic anticipation; since it is precisely the targeted argument that finally relieves this tension and fulfills this anticipation, it gets strong climactic emphasis (What Dostoevsky witnessed was A MURDER).

In the above example, the main verb of the basic proposition (witnessed) is part of what gets subordinated in the cleft version. But suppose the main verb of the basic proposition were a form of the verb $b$. For example, if the basic proposition were

Dostoevsky is a murder witness,

then the wh-cleft version targeting murder witness would be

What Dostoevsky is is a murder witness,

which of course has a perfectly grammatical double copula. Despite the rule of punctuation that a subject should not be separated from the predicate by a comma, some handbooks suggest inserting a comma between the two copulas, where (not incidentally) a pause or intonational shift occurs in speech. This pause or shift of intonation signals the boundary between the two clauses-that is, the area of "cleavage" in the cleftsentence construction. Thus, the first is belongs to the subordinate clause, and the second $i$ belongs to the main clause:

[What Dostoevsky is] IS A MURDER WITNESS. 
This is like (7) above, quoted from Sihler, which is also completely grammatical, with the first is belonging to the subordinate clause and the second is belonging to the main clause:

[What the problem is] IS STILL UNCLEAR.

But how does all of this apply to $(1)-(6)$ ?

Examples (1) and (3) could be analyzed as misfired efforts at the cleft construction. In both of these examples the double $i s$ may be just a false start or a restart at the point of "cleavage" in the cleft sentence-a stutter triggered by a crossing of the boundary between clauses. Perhaps these performance errors are also the result of analogizing from model cleft sentences like (7), analyzing them as instances of

[What $\mathrm{x}$ is] Is $\mathrm{Y}$.

instead of instances of the more general form

[What $\mathrm{x}$ verb] Is $\mathrm{y}$.

In any case, if the basic propositions of (1) and (3) had been cleft according to the latter formula, the results would have been perfectly grammatical:

I've said that . . $\rightarrow$ What I've said is that ...

I can say that . . $\rightarrow$ What I can say is that ...

These grammatical examples show that an entire nominal that-clause can also be the NP argument targeted for emphasis by the cleft construction.

This brings us to the second main point.

The instances of that in (1)-(6) above are complementizers introducing nominal clauses (dependent clauses that fill noun slots rather than relative clauses that modify nouns). The difference between nominal thatclauses and relative that-clauses can be illustrated by the following:

8. Tom rejects the theory that Fyodor accepts.

9. Tom rejects the theory that Fyodor is alive.

In sentence (8), that is a relative pronoun introducing a relative clause modifying theory, but in sentence (9), that is a complementizer introducing a noun-complement clause-a different kind of dependent clause, in that it complements (fleshes out the content of) theory, instead of merely modifying it. One evidence of the difference is the replaceability of that with the relative pronoun which in (8) but not in (9): 
Tom rejects the theory which Fyodor accepts.

*Tom rejects the theory which Fyodor is alive.

The importance of the difference is that the complementizer that, unlike the relative pronoun that, plays no argument role within the dependent clause that it introduces; it merely acts as a subordinator of that clause.

The that-clause in (9) complements (or here stands in apposition to) the head noun theory. That-clauses of this sort also stand alone in NP slots with no head noun:

I said a sentence.

I said that Fyodor is alive.

The complementizer that is optional in many sentences of this sort, where it is obvious that the clause following the main verb is subordinate, usually when the that-clause is the object of the sentence:

I know that Fyodor is alive.

I know Fyodor is alive.

But in other positions the nominal clause requires that in order to signal its subordination:

That you are always late bothers me.

*You are always late bothers me.

It bothers me that you are always late.

?It bothers me you are always late.

It is that you are always late that bothers me.

*It is you are always late that bothers me.

What bothers me is that you are always late.

?What bothers me is you are always late.

This dual nominalizing and subordinating function of that could explain its obligatory nature in constructions like (1)-(6). In the grammatical version of (6), for instance, omission of that would result in a complete reparsing of the structure, reducing the main clause to a disjunct:

The problem is that the payment always arrives late.

The problem is, the payment always arrives late.

Example (6), like (2), (4), and (5), is not exactly an unsuccessful cleft but an unsuccessful close approximation of the cleft. More precisely, these examples appear to be mixed constructions, confusing the cleft with its close approximation. The two forms are easy to confuse because their 
recipes are so similar when the argument targeted for emphasis is a nominal clause:

$w h$-cleft $=[w h$-nominal clause $]$ is [that-nominal clause $]$

approximation of cleft $=$ [ordinary $\mathrm{N}$ phrase $]$ is $[$ that-nominal clause $]$

This "relative of cleft" has almost all the same stylistic advantages possessed by the cleft itself: subordination of nonemphatic content, delay of closure, and end focus on a targeted argument. In fact, the cleft's slightly more sophisticated syntactic machinery hardly produces enough additional horsepower to justify itself; indeed, it gets in the way:

WH-CLEFT: What the problem is, Mr. Brown, is that the payment is always late. APproximation of CLEFT: The problem, Mr. Brown, is that the payment is always late.

In any case, this "approximation of the cleft" is clearly a competing form, so it is easy to understand why people would confuse the constructions and mix them.

Just what sort of "approximation of the cleft" is the simpler version? Well, if the cleft is derived from a simpler form (i.e., if cleft sentences can be systematically related to simpler statements of their fundamental assertions), then it should now be obvious that this so-called "approximation of the cleft" is nothing more than what we have been calling the "basic proposition" underlying the cleft:

The problem is that you're late $\rightarrow$ What the problem is is that you're late.

One could then explain examples (2) and (4)-(6) - all of which end as clefts, but none of which (unlike examples 1, 3, and 7) begin as clefts-by supposing that speakers who uttered them merely changed syntactic strategies at mid-sentence, starting with straightforward basic propositions, but then trying (too late) to make them more emphatic with fancier syntax.

The faulty syntax may also have been exacerbated by confusion with competing disjunct versions common in speech:

My concerns are [these]: you're not getting Smerdyakov, and you're not getting Smerdyakov.

Truth is, I don't know what I'm talking about.

The ratio is, only Hillary knows.

Problem is, the payment always arrives late because I don't have any money.

This line of reasoning puts the reduplicative copula in its proper syntactic context. However, it does not explain the obligatory presence of 
that immediately after is is (and are is, if we consider the second Bush example above as nonepisodic). ${ }^{3}$ If that is obligatory after $i s$, suppose we analyze $i$ s that as a morphological unit-an expanded or multiword subordinate conjunction. Then an understanding of what may have given rise to the syntactic innovation begins to take shape, perhaps along the following lines.

Sentences of the form $X$ is $Y$ contain the copula not simply in its existential meaning but as an expression of IDENTITY. Now, identity is-as is well known-a semantic state often realized in particular ways in syntax. When the copula of identity stands between two syntactically equivalent but heterogeneous constituents-topic noun to its left, dependent nominal clause headed by that to its right-the link between the two constituents can be interpreted to be asymmetrical, and this asymmetry tends to undermine the (inherent) meaning of identity. Compensatorily, then, the meaning of identity in the case of asymmetry between constituents on either side of the copula can be strengthened by inserting the reduplicative version of the copula as a proclitic, that is, as an element bound to (parasitic on) the syntactic element following it, that. This syntactic change in progress is aided by the fact that the word that, in its function as the head of a dependent clause, has an attenuated (secondary) deictic meaning vis-à-vis its primary function as a demonstrative. In the grammar of speakers who habitually utter (but probably would not write) what looks like a reduplicative copula, subordinator that in nominal dependent clauses after topic words plus is has changed from the simplex that to the complex is that. This development has the effect of expressing (diagrammatizing) the difference in syntactic function between demonstrative and complementizer versions of the same pronoun as a difference in morphological form, which is then its explanation (its teleological raison d'être). ${ }^{4}$

\section{NOTES}

1. While there are brief chat room discussions in the 199 os (e.g., on ADS-L), we were unable to find any earlier published analyses.

2. Translating this into more conventional terms, every word comports a range of meanings (sometimes called the primary and secondary meanings or connotations) that form a set or (simultaneous) syntagm. The latter term is relevant because the meanings are hierarchized, just as are the diacritic or distinctive features in a phonological syntagm. In the case of a word in topic position, the assertion of its existence, which is redundantly present in every semantic syntagm, while virtual, is also potentially more salient due to its syntactic function qua topic. This virtual existential meaning can be exterior- 
ized or linearized—made actual—by inserting the copula, the existential word par excellence. If this is what happens, then necessarily the right-hand boundary of the syntagm has changed, because what was once virtual and wholly within the syntagm has been made actual, thereby moving the boundary one position to the right.

3. This and the ABC soap opera example could simply be slips of the tongue and have nothing to do with is is.

4. It would be interesting to speculate just why this innovation arose in the $1990 \mathrm{os}$ and was apparently absent before that, but a discussion of causes is beyond the scope of this treatment of the construction.

\section{REFERENCES}

Kolln, Martha, and Robert Funk. 1998. Understanding English Grammar. 5th ed. Boston: Allyn and Bacon.

Shapiro, Michael. 1993. "Presidential Address [to the Semiotic Society of America]: The Boundary Question.” American Journal of Semiotics 10: $5^{-26}$.

Sihler, Andrew L. 2000. Language History: An Introduction. Amsterdam Studies in the Theory and History of Linguistic Science 191. Amsterdam: Benjamins. 